\title{
First Lumbrical Muscle Flap for Recurrence of Carpal Tunnel Syndrome: Anatomical Study and Surgical Technique
}

\section{Colgajo del primer músculo lumbrical para recidiva de síndrome del canal carpiano: estudio anatómico y técnica quirúrgica}

\author{
Esther Fernández Tormos'10 Fernando Corella Montoya ${ }^{1,2,3(0)}$ Blanca Del Campo Cereceda1(1) \\ Montserrat Ocampos Hernández ${ }^{1,2}$ Teresa Vázquez Osorio ${ }^{40}$ Ricardo Larrainzar Garijo 1,3 (1)
}

1 Orthopedic Surgery and Traumatology Service, Hospital Universitario Infanta Leonor, Madrid, Spain

${ }^{2}$ Hand Surgery Unit, Hospital Universitario Quironsalud, Madrid, Spain

${ }^{3}$ Department of Surgery, Facultad de Medicina, Universidad Complutense de Madrid, Madrid, Spain

${ }^{4}$ Department of Anatomy and Embryology, Facultad de Medicina, Universidad Complutense de Madrid, Madrid, Spain

Rev Iberam Cir Mano 2021;49:79-87.

\author{
Address for correspondence Fernando Corella Montoya, PhD, \\ Avenida de la Gran Vía del Este 80, Madrid, 28031, Spain \\ (e-mail: Fernando.corella@gmail.com).
}

\section{Abstract \\ Keywords \\ - recurrence of carpal tunnel syndrome \\ - first lumbrical muscle flap \\ - muscle flap}

Recurrence of carpal tunnel syndrome implies the reappearance of symptoms after release surgery. If the cause of recurrence is not an incomplete release, but a traction neuritis, the tendency is to add to the revision surgery of the carpal tunnel the use of flaps to cover the median nerve. These flaps establish a physical barrier between the nerve and the rest of the adjacent structures, preventing adhesions, and providing neovascularization and better nerve sliding.

In the present work, we detail a revision surgery in which the first lumbrical muscle is used as a covering flap. This flap has two benefits. Firstly, it acts as a vascularized coverage for the median nerve (avoiding the formation of fibrosis and favoring its sliding); secondly, a structure that takes up space is removed from the carpal tunnel, thus reducing the pressure within it.

Along with the explanation of the technique, the present article provides a detailed description of the anatomical variability of the first lumbrical muscle and its vascularization, as well as the results of a cadaveric study on the location of the vascular pedicle of the first lumbrical muscle. received

February 7, 2021

accepted

March 8, 2021
DOI https://doi.org/ $10.1055 / \mathrm{s}-0041-1730391$. ISSN 1698-8396. (c) 2021. SECMA Foundation. All rights reserved.

This is an open access article published by Thieme under the terms of the Creative Commons Attribution-NonDerivative-NonCommercial-License, permitting copying and reproduction so long as the original work is given appropriate credit. Contents may not be used for commercial purposes, or adapted, remixed, transformed or built upon. (https://creativecommons.org/ licenses/by-nc-nd/4.0/)

Thieme Revinter Publicações Ltda., Rua do Matoso 170, Rio de Janeiro, RJ, CEP 20270-135, Brazil 


\section{Resumen}

Palabras clave
- recidiva de síndrome
de túnel carpiano
- colgajo primer
lumbrical
- colgajo muscular

La recidiva del síndrome del canal carpiano implica la reaparición de síntomas tras la cirugía de liberación. Si la causa de recidiva no es una apertura incompleta, sino una neuritis de tracción, la tendencia es añadir a la cirugía de revisión del canal carpiano la utilización de colgajos de cobertura del nervio mediano. Estos colgajos establecen una barrera física entre el nervio y el resto de las estructuras adyacentes, previniendo adherencias, aportando neovascularización, y proporcionanando un mejor deslizamiento nervioso.

En el presente trabajo, se detalla la cirugía de revisión en la que se utiliza el primer lumbrical como colgajo de cobertura. Este colgajo tiene dos beneficios. En primer lugar, sirve como cobertura vascularizada del nervio mediano (evitando la formación de fibrosis y favoreciendo su deslizamiento), y, en segundo lugar, se retira del canal carpiano una estructura ocupante de espacio, disminuyendo así la presión dentro del mismo.

Además de la explicación de la técnica, en este artículo se realiza una descripción detallada de la variabilidad anatómica del primer lumbrical y su vascularización, junto con los resultados de un estudio en cadáver sobre la localización del pedículo vascular del primer lumbrical.

\section{Introduction}

Carpal tunnel syndrome (CTS) is one of the most frequent reasons for consultation in hand surgery. The type of treatment is determined by the severity of the median-nerve neuropathy. Usually, in the case of mild-moderate neuropathies, orthopedic treatment is recommended in at first, but, if the patient continues to be symptomatic or if the neuropathy is severe, surgical treatment is indicated. Due to the high prevalence of the pathology and the apparent simplicity of carpal tunnel surgery, cases of failure of the surgical technique are not uncommon, and they also have complex solutions and poor results. ${ }^{1}$

Studies indicate that the failure rate after CTS surgery ranges from $3 \%$ to $25 \%{ }^{2}$ Three different situations are understood as failures. First, the persistence of symptoms after the intervention, which, in most cases, is explained by an incomplete release of the carpal tunnel. Second, the worsening after surgery, which can be caused by intraoperative nerve injury. Third and last, the recurrence of symptoms after an asymptomatic period, which is usually due to traction neuritis caused by scar tissue around the median nerve.

Recurrence therefore implies the reappearance of symptoms. If the symptoms begin in the first postoperative year, some authors advocate simple revision of the carpal tunnel. On the other hand, if it reappears after that period, the tendency is to add to the revision the use of covering flaps for the median nerve. ${ }^{1}$ These flaps establish a physical barrier between the nerve and the rest of the structures, preventing adhesions, and providing neovascularization and better nerve gliding. ${ }^{3,4}$

It should be noted that those studies ${ }^{5,6}$ that compare the simple revision of the median nerve with the revision with use of covering flaps show better results in surgeries that include flaps. The flaps can be fatty, synovial, fasciocuta- neous or muscular. But currently there are no studies in the literature comparing the different types and describing clinical differences.

\section{Surgical Indication and Justification}

The fundamental surgical indication for the first lumbrical muscle flap is the treatment of symptomatic recurrence of CTS.

It is a type of muscle flap described in 1998 by Koncilia et al. ${ }^{7}$ Besides the treatment of CTS recurrence other uses of this flap have also been described, such as in the treatment of neuromas and palmar tendocutaneous fistulas.

The incursion of the lumbrical muscles into the carpal tunnel has been considered a possible cause of CTS. In cadaveric studies, ${ }^{8}$ the degree of incursion of the lumbrical muscles has been shown to increase with flexion of the fingers. It has also been proven that this increase in incursion is followed by an increase in pressure proportional to the degree of flexion of the fingers.

Thus, in extension, they are found on average to $7.8 \mathrm{~mm}$ distal to the carpal tunnel, in $50 \%$ of flexion of the fingers, $14 \mathrm{~mm}$ are inserted into the carpal tunnel, in $75 \%$, they penetrate $25.5 \mathrm{~mm}$, and, in $100 \%$ of flexion, $30 \mathrm{~mm}$. It has also been proven that this increase in incursion is followed by an increase in pressure, which in turn increases with the degree of flexion of the fingers. If the lumbrical muscles are resected, the increase in pressure does not occur despite the flexion of the fingers. ${ }^{8}$ Lumbrical muscles have also been reported as a reason for CTS in young manual workers whose jobs required repetitive movements of the hand. In this group of patients, the lumbricals were larger and had a more proximal origin than in the rest of the population. ${ }^{9}$

Given all the aforementioned information, the first lumbrical flap as a treatment for CTS recurrence provides two effects. Firstly, it acts as a vascularized covering for the 
median nerve, preventing the formation of fibrosis on it, and, secondly, a structure that takes up is removed from the carpal tunnel, thus reducing the pressure within it. For these reasons, of all the flaps described, the authors of the present study prefer the first lumbrical muscle flap.

The present article has two objectives. Firstly, to describe the anatomical variability of the first lumbrical muscle and its vascularization, as a review of the surgical anatomy. For this, a literature review will be carried out, and the results of our dissection study will be presented. Secondly, the surgical technique will be detailed and explained step by step.

\section{Surgical Anatomy. Anatomical Variability of the First Lumbrical Muscle}

\section{Literature Review}

There are four lumbrical muscles in the palm of the hand. Their origin is the deep flexor of the fingers, and their insertion is in the radial band of the extensors, palmarly and distally to the intermetacarpal ligaments. The two most ulnar lumbrical muscles are bipennate, and the two most radial are unipennate. All of them fulfill a function of extension of the interphalangeal joint and flexion of the metacarpophalangeal joint. ${ }^{7,10}$ The first lumbrical muscle presents the most constant anatomy among them, while the more ulnar the lumbrical muscle, the greater the anatomical variability.

As for the vascularization of the hand, it depends on an arterial network in which we distinguish the superficial the deep palmar arches, with great anatomical variability. It is important to know the anatomical variability of the superficial palmar arch, since it is responsible for the main vascularization of the first lumbrical.

In the first descriptions made by Keen, ${ }^{11} 3$ types of superficial palmar arch are listed: the "ulnar" type, with minimal or absent radial artery, prevalent in $59 \%$ of cases, the "radioulnar" type (32\%), in which the radial artery has a contribution similar to that of the ulnar artery, and the "median-ulnar" type, in which the median artery is sufficiently large to reach the palm and form part of the arch, with a prevalence of $9 \%$.

The meta-analysis conducted by Zarzecki et al. ${ }^{12}$ includes 4,841 palmar arches. They describe that the superficial palmar arch may have a radioulnar anastomosis, or arch closure, prevalent in $81.3 \%$ of the cases (complete palmar arch), while the remaining $18.7 \%$ present an incomplete palmar arch, that is, without closure. In their study on 55 hands, Gnanasekaran and Veeramani ${ }^{13}$ obtained results similar to the conclusions of the aforementioned meta-analysis, with $80 \%$ of specimens with arch closure, compared to $20 \%$ with incomplete arches. This study also includes a classification of complete arches into 6 categories, and incomplete arches into 5 types, depending on the anastomoses and branches for the thumb and other triphalangeal fingers.

Gellman et al., ${ }^{14}$ in a study on 95 specimens, obtained data comparable to those previously described, with closure of the arch in around $85 \%$ of the hands analyzed, and around $15 \%$ without closure.

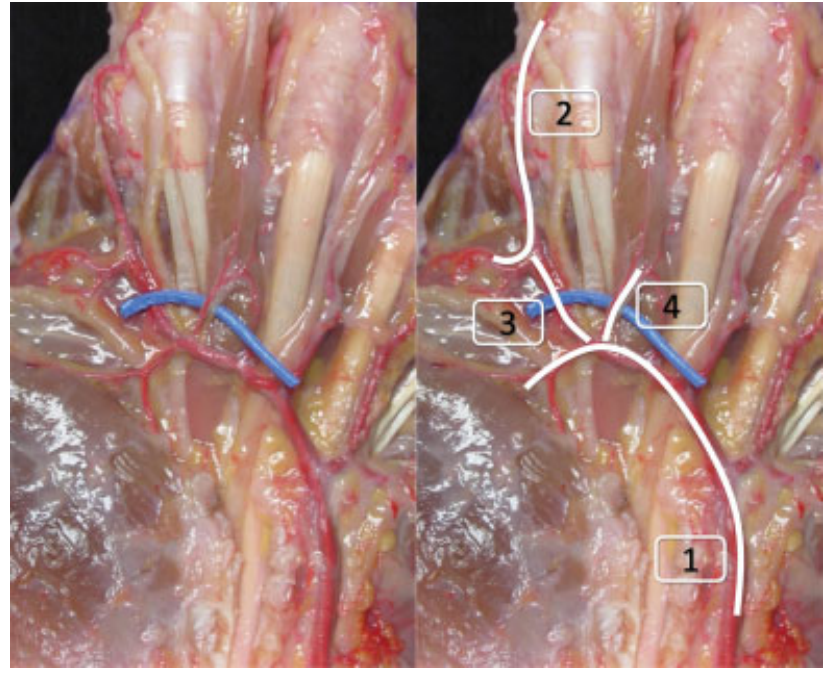

Fig. 1 Surgical anatomy around the pedicle of the first lumbrical muscle. Superficial arch (1); radial artery of the index finger (2); communicating artery (3); pedicle of the first lumbrical muscle (4).

Regarding the vascularization of the lumbrical muscles, studies are scarce. Their irrigation depends mainly on the superficial palmar arch, and, to a lesser extent (its distal third), on the deep palmar arch through the metacarpal artery. The anatomical study by Zbrodowski et al. ${ }^{15}$ is noteworthy; it includes 100 specimens and the authors describe in detail the vascularization of the lumbrical muscles. The first lumbrical muscle, receives vascularization from most of the arterial branches; on the other hand, these constitute the smallest plexus of all the lumbrical muscles.

In relation to the main pedicle, on which we base the flap, it can come either from the communicating artery between the radial artery of the index finger and the superficial palmar arch, or ir can originate directly from the superficial palmar arch (-Figure 1). If there is no arch closure, the pedicle may come from the median, ulnar, or radiopalmar arteries. $^{10}$

\section{Cadaveric Study}

\section{Material and Method}

The present is an anatomical analysis of 25 fresh specimens from Centro de Donación de Cuerpos of Universidad Complutense de Madrid, previously injected with latex through the radial and ulnar arteries. The specimens were 16 men (64\%) and 9 women (36\%) with an average age of 77 years (range: 35 to 100 years) who had neither suffered any trauma nor had been submitted to previous surgery on the hand.

A careful dissection was carried out on the pieces by planes with magnifying glasses with a magnification of $3.5 \mathrm{x}$. All the measurements reported in the present article were performed by two surgeons using an Absolute Digital Caliper (Mitutoyo, Kanagawa, Japan), with an accuracy of $0.002 \mathrm{~mm}$.

It began with the dissection of the skin, subcutaneous, superficial fascia, and palmar aponeurosis. In the subaponeurotic plane, the superficial palmar arch was dissected, as 


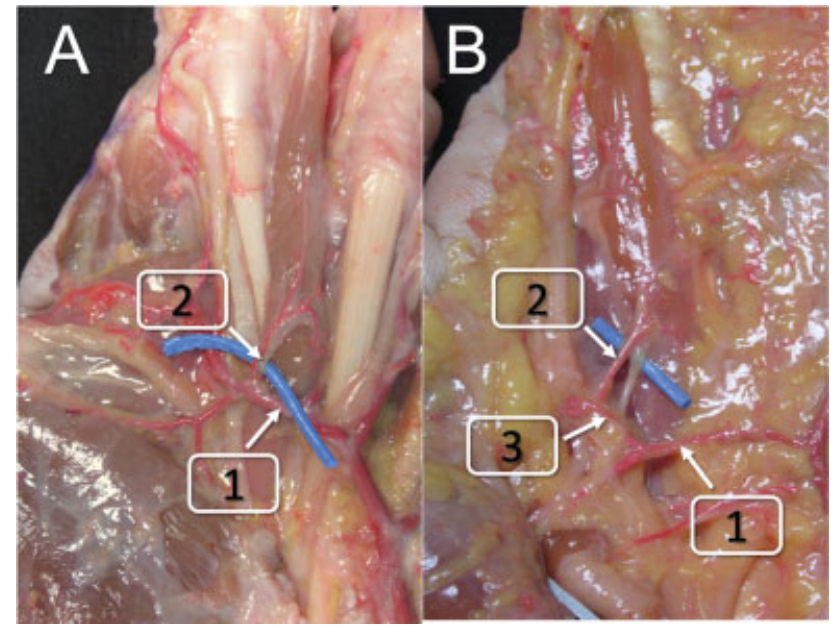

Fig. 2 Origin of the main pedicle of the first lumbrical muscle. (A) Origin in the superficial palmar arch. Superficial arch (1); pedicle of the first lumbrical muscle (2). (B) Origin in the communicating artery. Superficial palmar arch (1); pedicle of the first lumbrical muscle (2); communicating artery (3).

well as its branches, and the radial artery and the radial collateral nerve of the index finger.

We studied the anatomy of the superficial palmar arch, reviewing the existence or not of the arch closure. Later, the first lumbrical muscle was dissected, respecting its vascularization and innervation. Subsequently, the artery of the main pedicle of the first lumbrical muscle was identified, and we described its origin and its distance from the superficial palmar arch.

\section{Results}

In total, $80 \%$ (20/25) of the specimens had a closed superficial palmar arch, while $20 \%(5 / 25)$ had an open palmar arch.

In $11 / 25$ specimens (55\%), the main pedicle of the first lumbrical muscle came from the arch itself, and, in 9/25 specimens (45\%), it came from a communicating artery. In these cases, the average distance from the origin of the pedicle to the superficial palmar arch was of $8.37 \mathrm{~mm}$ (-Figure 2).

In $20 \%(5 / 25)$, no closure of the superficial palmar arch was found. In 3 out of these 5 specimens (12\%) the main pedicle originated from the median artery, in the remaining $2(8 \%), 1$ came from the ulnar artery, and the other, from the radiopalmar artery (-Figure 3 ).

\section{Surgical and Postoperative Technique}

\section{Surgical Technique}

\section{Setup and Position of the Patient}

The surgical intervention is performed with ischemia in the root of the limb and its extremity on the hand table. Ischemia is not performed with an Esmarch bandage, but by elevation in order to better identify the vascular pedicle of the first lumbrical muscle. Given the size of the pedicle and the

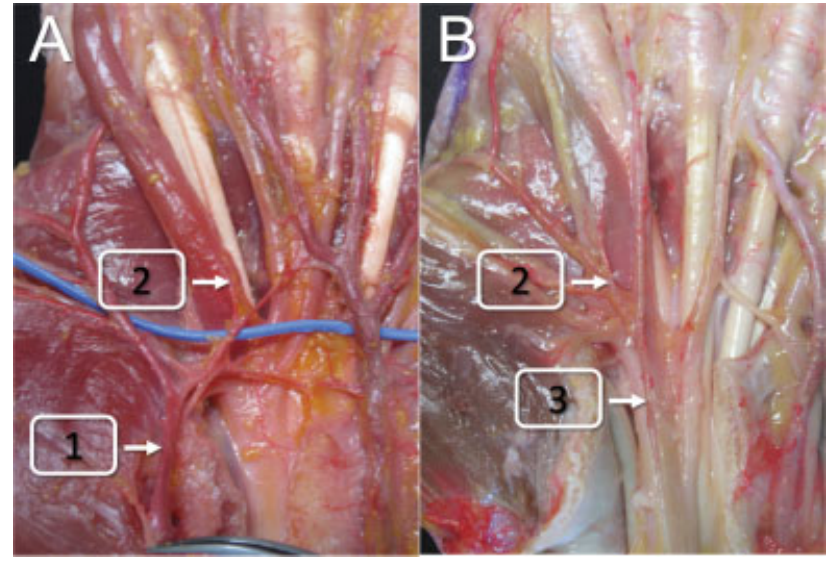

Fig. 3 Origin of the main pedicle of the first lumbrical muscle in specimens without closure of the superficial palmar arch. (A) Origin in the radiopalmar artery (1); pedicle of the first lumbrical (2). (B) Origin in the median artery (3).

structures at risk, it is essential to use magnifying glasses to identify the structures during the intervention.

\section{Skin Incision}

To perform the incision, the previous scar on the carpal tunnel is taken as a guide, and it is expanded distally towards the radial side of the second finger, in the first interdigital space, following as much as possible flexion lines of the palm.

The scar should also be extended proximally, crossing the wrist crease in a zigzag manner, to comfortably proceed to explore the median nerve proximally and free all possible adhesions (-Figure 4).

\section{Opening of the Carpal Tunnel and Neurolysis}

Always and prior to the elaboration of the flap, a revision of the carpal tunnel should be carried out, as well as the identification and release of possible adhesions of the nerve to adjacent structures ( $\mathbf{- F i g u r e ~} \mathbf{5}$ ). Once the nerve has been released at the level of the carpal tunnel, the identification

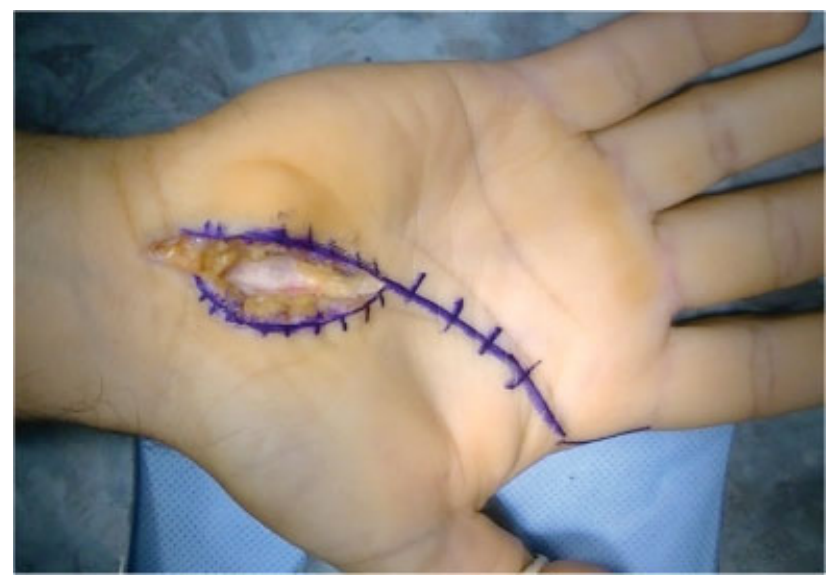

Fig. 4 Approach for the first lumbrical muscle flap. Incision over a previous scar to reopen the carpal tunnel and expose the nerve. The incision extends distally to the previous scar towards the radial side of the base of the second finger, and proximally across the distal and proximal palmar creases of the wrist. 


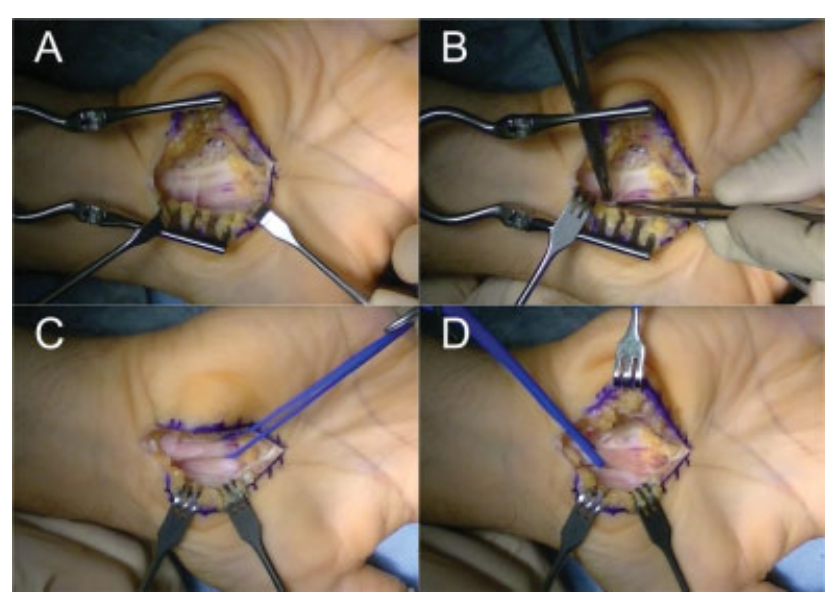

Fig. 5 (A) Opening over a previous scar. The scar tissue that squeezes the median nerve can be seen. (B) Neurolysis of the median nerve. (C-D) Release of proximal and distal adhesions is verified.

and reference of its branches will avoid a possible iatrogenic injury.

\section{Location and Dissection of the First Lumbrical Muscle} In this step, the skin incision is continued distally to the root of the second finger. The palmar aponeurosis is identified, and just below it, the radial nerve of the index; then, the first lumbrical is released until its complete exposure (-Figure 6).

Once the entire approach has been exposed, the entire superficial palmar arch is identified, which, as aforementioned, can be complete or incomplete. The main pedicle of the first lumbrical muscle is found at the junction of the proximal and middle thirds of the first lumbrical muscle, and can arise directly from the superficial palmar arch or from the communicating artery.

A technical detail that facilitates the identification of the vascular pedicle, if it is not easily located, is the identification of the nerve that innervates it and that arises from the radial digital nerve. The innervation pedicle is often easier to identify than the vascular pedicle; the vascular pedicle is reached by raising the nerve and following it (both penetrate in the same location into the muscle) (-Figure 7).

\section{Median Nerve Coverage with the First Lumbrical Muscle} The dissection and separation of the first lumbrical muscle from the deep flexor tendon is executed from distal to proximal. It begins by cutting its distal tendon of insertion and continues proximally, taking care not to injure its vascular pedicle during its separation.That is why the identification of the pedicle in the previous step is essential (-Figure 8).

The separation of the lumbrical muscle from the deep flexor must extend to the vascular pedicle, maintaining the most proximal union or performing a complete detachment, leaving only the lumbrical muscle united by the vascular pedicle. Performing a full release or maintaining the most proximal insertion depends on whether or not full coverage of the nerve is achieved.

Once disinserted, the first lumbrical muscle is rotated proximally to cover the carpal tunnel, carefully ensuring that the pedicle is not under much tension or rotated (- Figure 9). With this, full coverage of the median nerve is practically

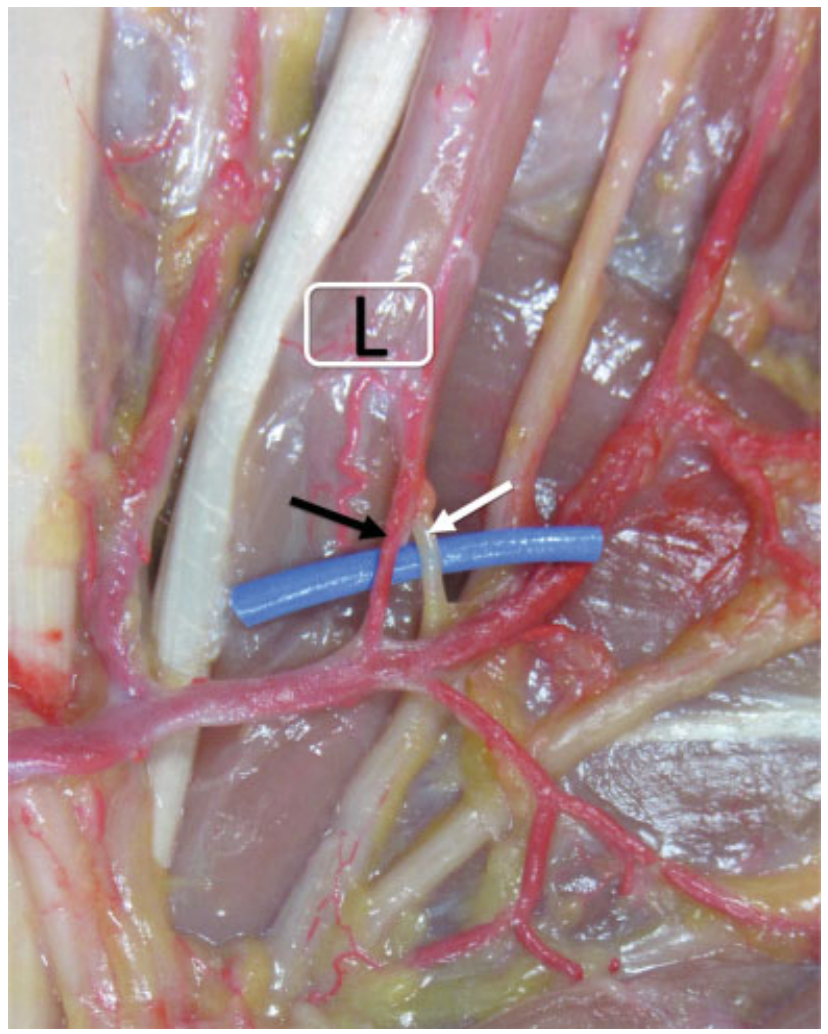

Fig. 7 Entry of the neurovascular pedicle into the lumbrical muscle (L). The nerve originates from the radial digital nerve of the index finger (white arrow), and the vascular pedicle (black arrow) enters the lumbrical in the same location as that of the nerve.

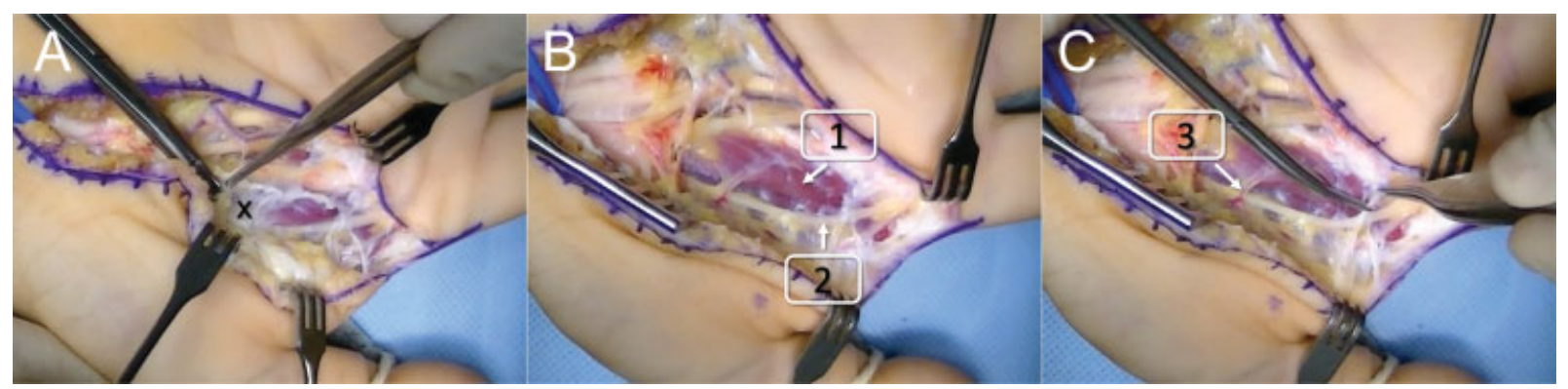

Fig. 6 (A-C) The palmar aponeurosis $(x)$ is identified, and the radial nerve of the index is released (2). The first lumbrical muscle (1) is located just below the aponeurosis, and its pedicle is identified (3) entering through its most radial portion. 


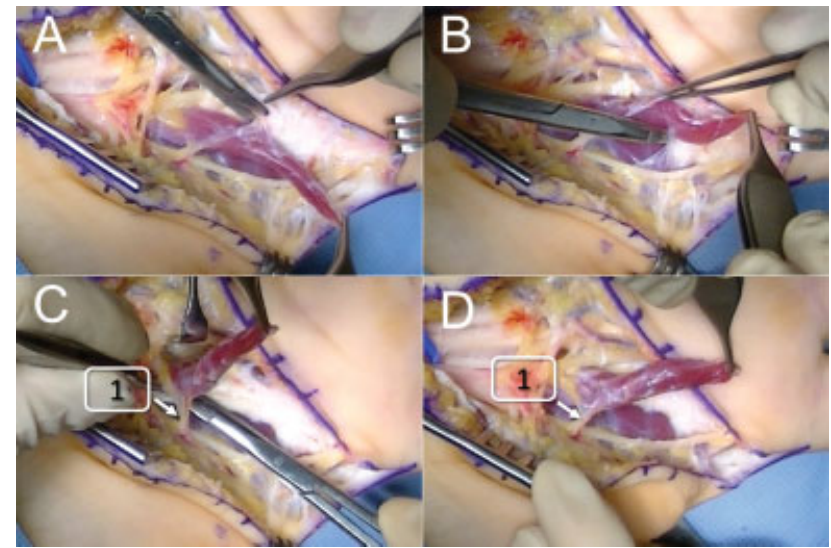

Fig. 8 Dissection of the first lumbrical muscle. (A-B) Dissection of the first lumbrical muscle and separation of the tendon and the aponeurosis. This dissection should be performed with caution so as not to injure the radial digital nerve of the index finger. (C-D) The distal insertion of the first lumbrical muscle is released, and the disinsertion continues proximally. In this step, caution not to damage the pedicle (1).

always achieved in those patients in whom the closure of the superficial palmar arch is incomplete. However, in those with complete closure, complete coverage of the median nerve is not always achieved in the most proximal portion. In these cases, a technical detail that makes it possible to reach more proximally is to rotate the muscle below the palmar arch. We must be very careful so that the pedicle does not rotate or is injured when passing under it, but in this way we almost always obtain complete coverage of the nerve, by gaining reach of the flap. ( $\mathbf{- F i g u r e ~ 1 0 ) . ~}$

Subsequently, we proceed to the longitudinal opening of the muscle epimysium, which enables the opening of the muscle belly as a book, in such a way that a thin and regular muscle layer is obtained (-Figure 11). Finally, this muscle layer is sutured to the remains of the transverse ligament

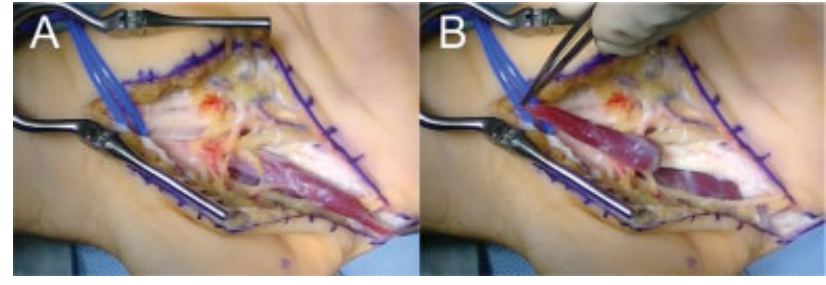

Fig. 9 (A) First lumbrical muscle dissected and distally disinserted. (B) Rotation of the muscle to cover the carpal tunnel.

that limits the carpal tunnel radially and ulnarly with a

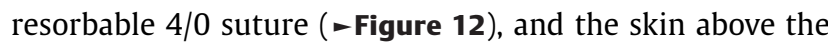
flap is closed directly with a $5 / 0$ monofilament.

\section{Postoperative Management}

The patient leaves the operating room immobilized with a dorsal brachipalmar splint for pain control and protection of the flap.

Weekly dressings are performed, the sutures are removed after two weeks, and the splint, on the third week. Specific rehabilitation treatment focused on restoring strength and mobility is then started.

The postoperative period is similar to that of other types of flaps described in the literature (fatty, muscular, synovial and fasciocutaneous).

\section{Clinical Case}

A 73-year-old patient with no relevant medical history. After years of symptoms compatible with compression neuropathy of the median nerve, an electromyographic study was performed, in which a moderate-severe compressive neuropathy of the median nerve was diagnosed, for which a carpal tunnel unroofing surgery was performed. The initial evolution was satisfactory, without complications of the

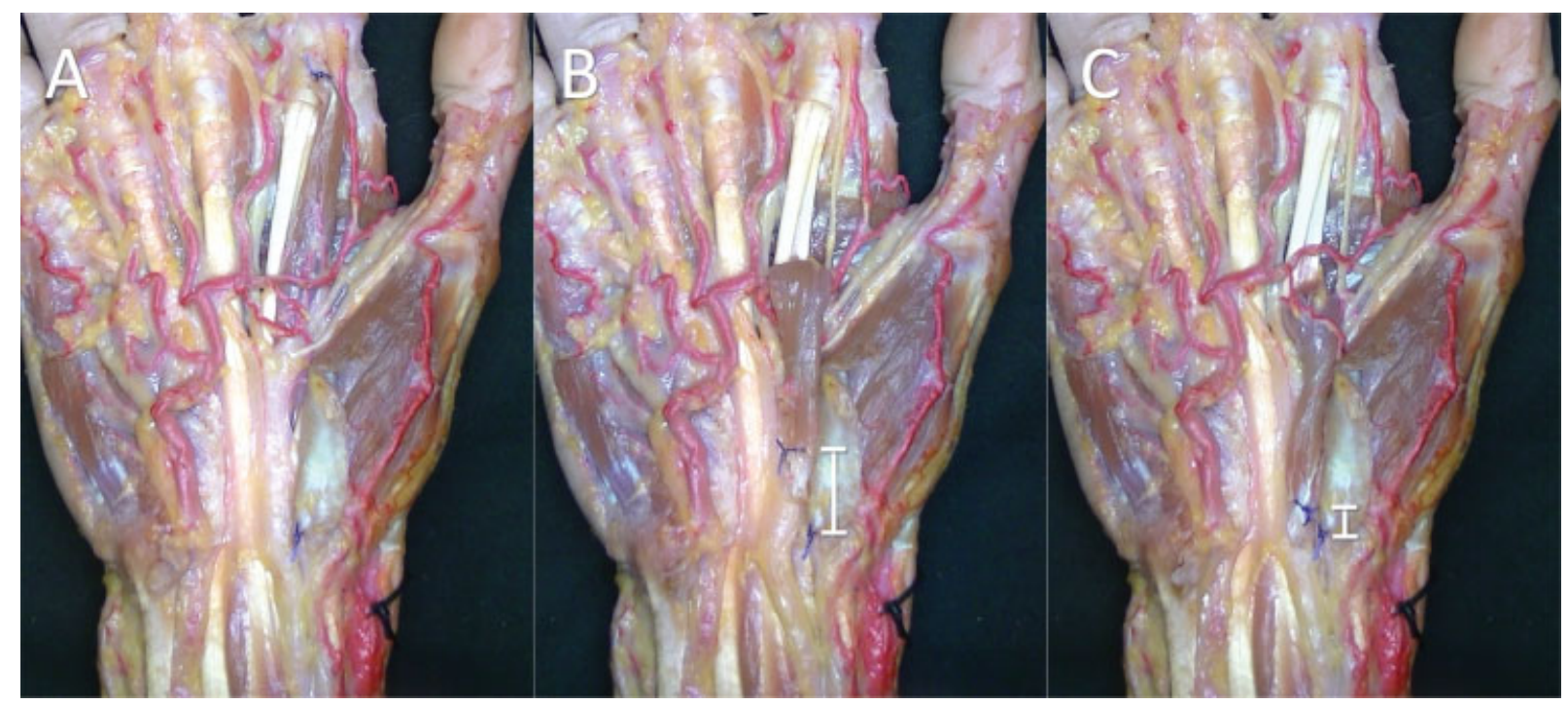

Fig. 10 (A) Anatomical dissection with the dissected lumbrical muscle in its normal position. The myotendinous junction was marked with one suture, and the trapezial ridge, with another suture. (B) Rotation of the muscle above the palmar arch. (C) Rotation of the muscle below the palmar arch. It is observed that the distance that is reached proximally is much greater rotating the muscle below the palmar arch. 


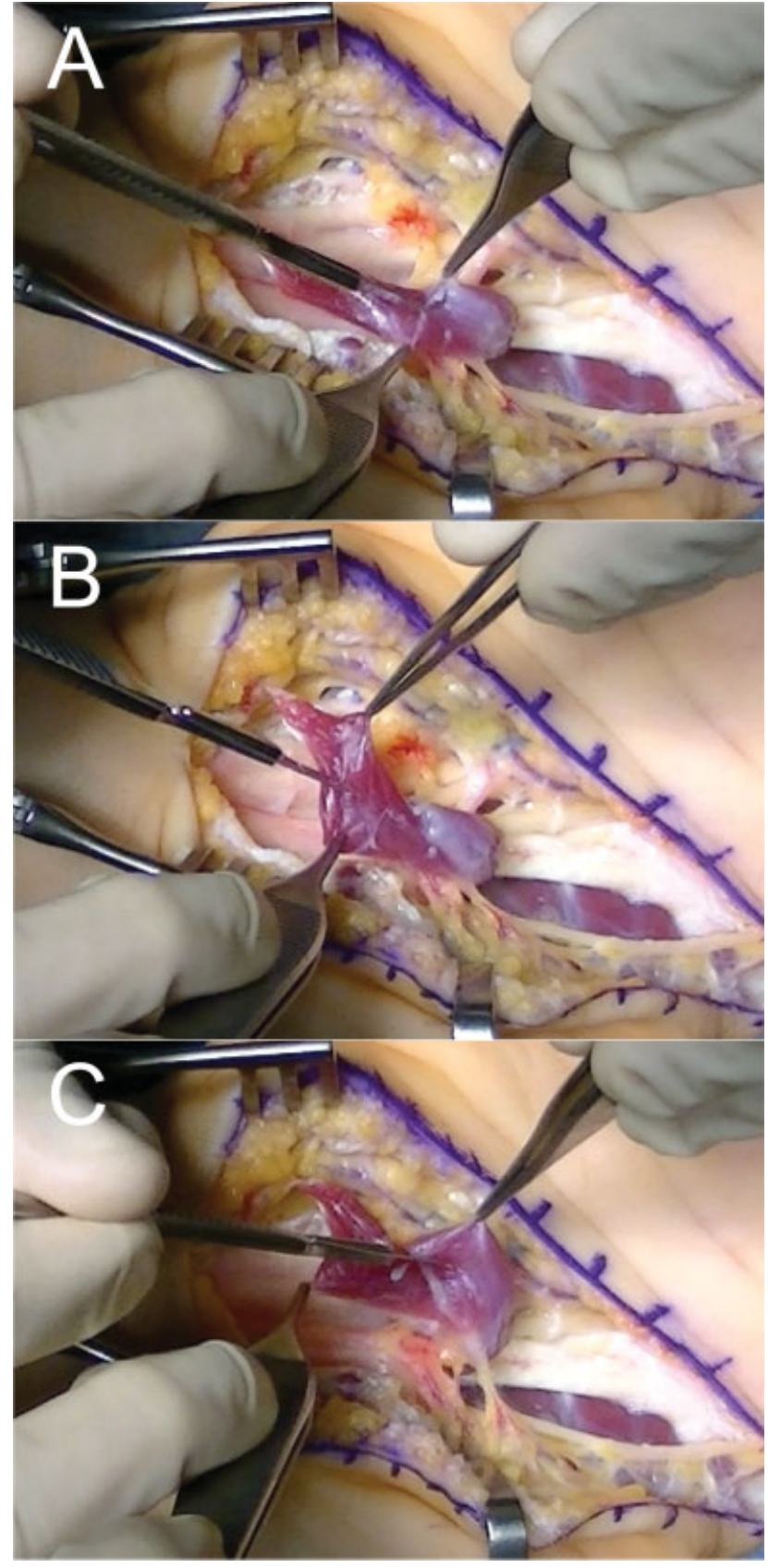

Fig. 11 (A-C) Rotation of the first lumbrical muscle and opening of the epimysium to obtain a uniform and fine muscular layer.

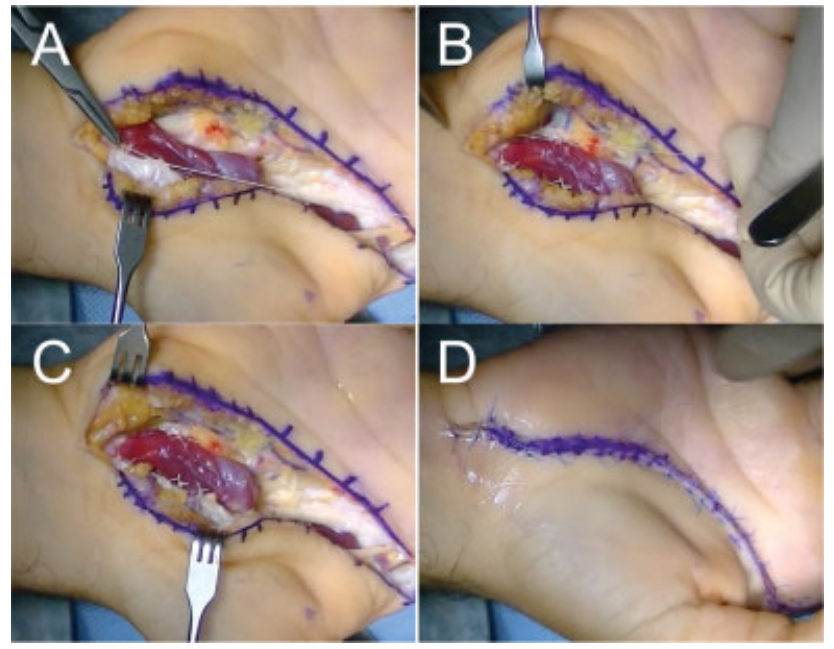

Fig. 12 (A-B) Complete coverage of the carpal tunnel with the first lumbrical muscle. Once the epimysium is open, the muscle is sutured to the walls of the carpal tunnel, covering the median nerve. (C) Final result: the muscle covers the entire carpal tunnel. (D) Cutaneous closure with 5/0 monofilament.

surgical wound, but with progressive clinical worsening a month after the surgery.

A magnetic resonance imaging (MRI) scan was performed, in which edema of the median nerve and scar tissue around the nerve under the opening area were observed; threfore, we decided to perform revision surgery (-Figure 13).

During the surgery, a complete opening of the flexor retinaculum was observed along with scar tissue around the nerve, producing a traction neuritis, so we decided to release the nerve from the scar tissue (-Figure 14), along with the coverage by the first lumbrical muscle flap (-Figure 15).

The postoperative evolution was satisfactory, with progressive improvement in sensitivity and recovery from thenar amyotrophy.

\section{Conclusions}

Recurrence of CTS after surgery is a relatively frequent problem, with complex surgical solutions and no consensus on which is the optimal one.

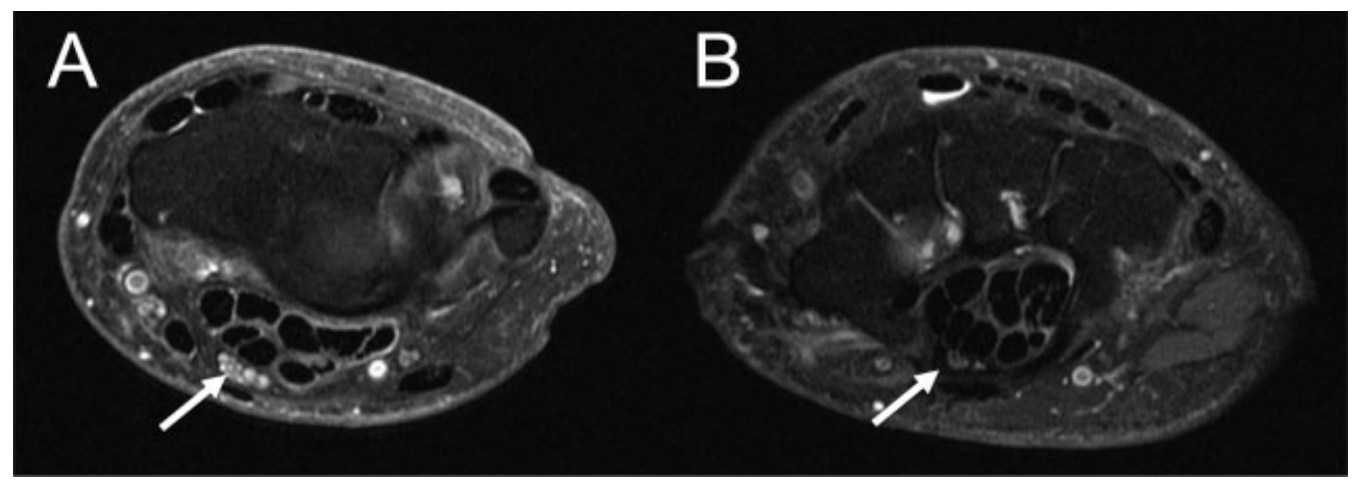

Fig. 13 (A) T2 MRI sequence showing a hyperintense signal from the median nerve prior to entry into the carpal tunnel. (B) Image of carpal tunnel opening with thinning of the nerve and surrounding scar tissue. 


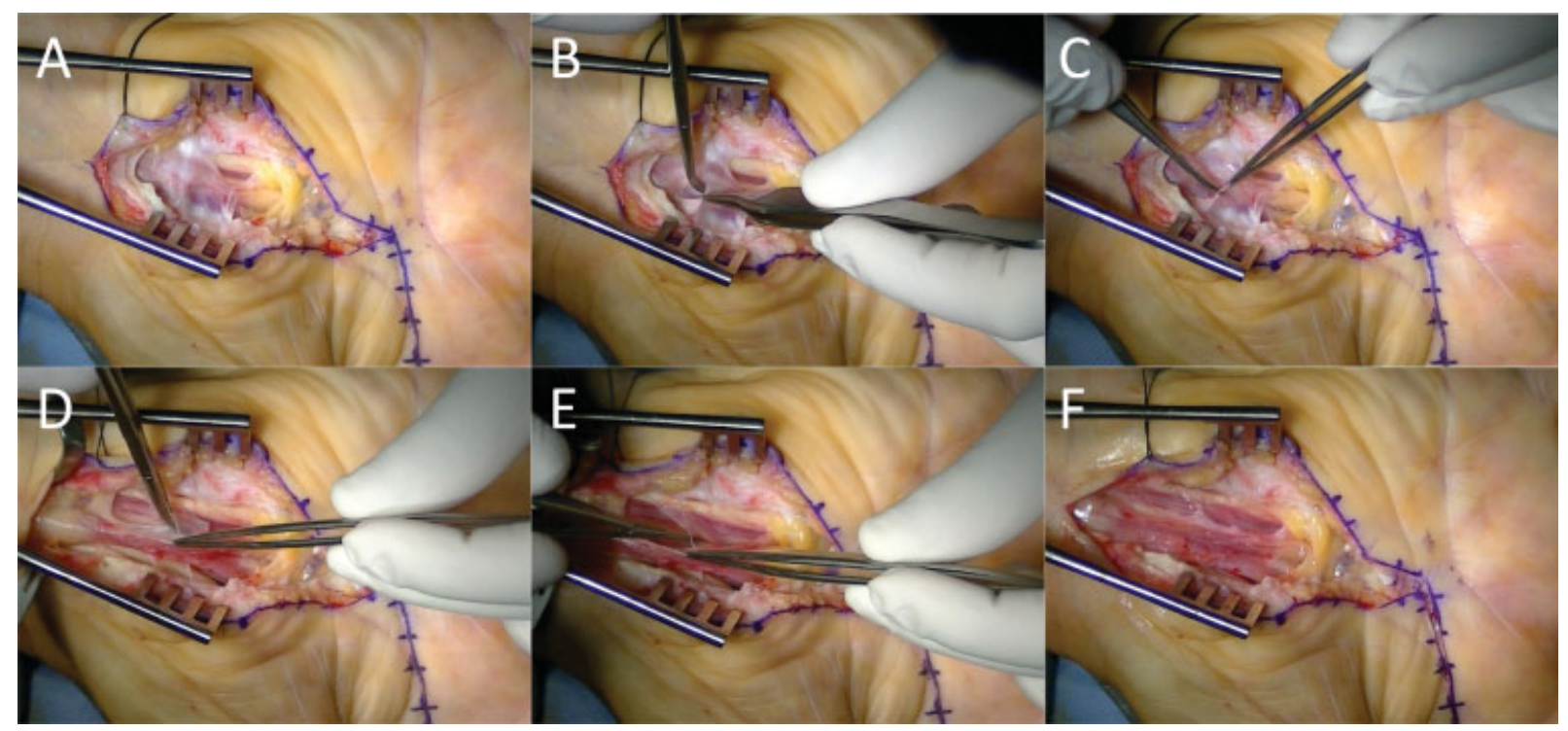

Fig. 14 (A) There is significant scar tissue around the median nerve, squeezing it. (B-E) Neurolysis of the median nerve, releasing all the adhesions to the surrounding tissue. (F) Released median nerve.

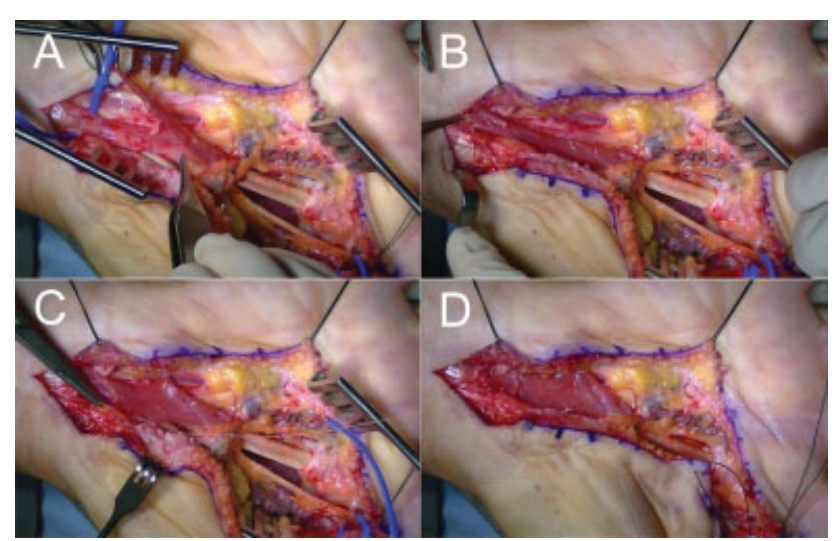

Fig. 15 (A) The first lumbrical muscle is passed under the palmar arch to achieve greater coverage in the proximal area. (B-C) Suture of the muscle to the walls of the carpal tunnel. (D) Complete coverage of the median nerve.

The first lumbrical muscle flap is a reproducible technique. It also has advantages over other flaps, since it eliminates a cause of compression of the median nerve, besides offering adequate coverage and vascularization to the nerve.

Before executing the technique, it is essential to know the different anatomical variants, since they condition the surgery and prevent iatrogenesis. As we have described in the technique, the most demanding step in the surgery is to find the vascular pedicle and dissect the superficial palmar arch. Therefore, it is very important to identify the different types of palmar arch and to know that the pedicle can come directly from the arch or have its origin in the communicating artery.

Therefore, the performance of anatomical studies such as the present is essential to master the anatomy, improve the available techniques, and achieve surgical success.

Our contribution to the original technique, in addition to the anatomical study, is the transfer of the flap below the superficial palmar arch. This simple gesture enabled us to increase the reach of the lumbrical flap, ensuring correct coverage of the median nerve, even in cases with complete closure of the superficial palmar arch.

\section{Conflict of Interests}

The authors have no conflict of interests to declare.

\section{References}

1 Steyers CM. Recurrent carpal tunnel syndrome. Hand Clin 2002; 18(02):339-345

2 Jones NF, Ahn HC, Eo S. Revision surgery for persistent and recurrent carpal tunnel syndrome and for failed carpal tunnel release. Plast Reconstr Surg 2012;129(03):683-692

3 Amadio PC. Interventions for recurrent/persistent carpal tunnel syndrome after carpal tunnel release. J Hand Surg Am 2009;34 (07):1320-1322

4 Abzug JM, Jacoby SM, Osterman AL. Surgical options for recalcitrant carpal tunnel syndrome with perineural fibrosis. Hand (N Y) 2012;7(01):23-29

5 Sameem M, Au M, Wood T, Farrokhyar F, Mahoney J. A systematic review of complication and recurrence rates of musculocutaneous, fasciocutaneous, and perforator-based flaps for treatment of pressure sores. Plast Reconstr Surg 2012;130(01):67e-77e

6 Soltani AM, Allan BJ, Best MJ, Mir HS, Panthaki ZJ. A systematic review of the literature on the outcomes of treatment for recurrent and persistent carpal tunnel syndrome. Plast Reconstr Surg 2013;132(01):114-121

7 Koncilia H, Kuzbari R, Worseg A, Tschabitscher M, Holle J. The lumbrical muscle flap: anatomic study and clinical application. J Hand Surg Am 1998;23(01):111-119

8 Cobb TK, An KN, Cooney WP. Effect of lumbrical muscle incursion within the carpal tunnel on carpal tunnel pressure: a cadaveric study. J Hand Surg Am 1995;20(02):186-192

9 Siegel DB, Kuzma G, Eakins D. Anatomic investigation of the role of the lumbrical muscles in carpal tunnel syndrome. J Hand Surg Am 1995;20(05):860-863

10 Palti R, Vigler M. Anatomy and function of lumbrical muscles. Hand Clin 2012;28(01):13-17

11 Keen JA. A study of the arterial variations in the limbs, with special reference to symmetry of vascular patterns. Am J Anat 1961; 108:245-261 
12 Zarzecki MP, Popieluszko P, Zayachkowski A, Pękala PA, Henry BM, Tomaszewski KA. The surgical anatomy of the superficial and deep palmar arches: A Meta-analysis. J Plast Reconstr Aesthet Surg 2018;71(11):1577-1592

13 Gnanasekaran D, Veeramani R. Newer insights in the anatomy of superficial palmar arch. Surg Radiol Anat 2019;41(07):791-799
14 Gellman H, Botte MJ, Shankwiler J, Gelberman RH. Arterial patterns of the deep and superficial palmar arches. Clin Orthop Relat Res 2001;(383):41-46

15 Zbrodowski A, Mariéthoz E, Bednarkiewicz M, Gajisin S. The blood supply of the lumbrical muscles. J Hand Surg [Br] 1998;23(03): 384-388 